Pediat.Res. 2: 486-492 (1968)

Chromosomes hallucinogens

fetus leukocytes

genetics lysergic acid

\title{
The Effect of LSD-25 on the Chromosomes of Children Exposed in Utero
}

\author{
Marmon M. Cohen ${ }^{[41]}$, Kurt Hirschhorn, Susan Verbo, William A. Frosch and \\ Moya M. Groeschel \\ Department of Pediatrics, State University of New York at Buffalo Medical School, \\ and Buffalo Children's Hospital, Buffalo, New York; \\ Department of Pediatrics, Mt. Sinai School of Medicine, New York, New York; \\ Department of Psychiatry, New York University School of Medicine and Bellevue Hospital \\ Psychiatric Division, New York, New York, USA
}

\begin{abstract}
Extract
This paper reports the cytogenetic investigation of nine children exposed to LSD-25 in utero, four children of other LSD users not exposed in utero, the mothers of these children, and six additional adults taking the drug. In comparison with matched controls, significantly elevated frequencies of chromosomal damage were observed in all the individuals exposed. The frequencies of aberrations, however, were markedly reduced in those children not exposed in utero. Eight structural rearrangements were observed, six dicentric chromosomes and two quadriradial formations, among those individuals exposed to the drug, but none was observed in the controls. In spite of obvious chromosomal aberrations, all of the individuals in this study were apparently healthy and showed no obvious birth defects.
\end{abstract}

\section{Speculation}

The significance of chromosomal damage produced in utero by pharmacologic agents and observed in the circulating lymphocytes of exposed infants and children remains controversial. Analogies have been drawn which suggest possible consequences of these lesions. The present study documents chromosomal damage in somatic cells of patients lacking any physical abnormality and reemphasizes the necessity for defining the extent to which chromosomal imbalance can be tolerated without phenotypic deviation. One can only speculate on possible biological events were such agents to affect the chromosomes of spermatagonial cells and thus yield defective gamates. Were this to eventuate, drugs with chromosome-breaking potential could act as powerful mutagens and have effects persisting into subsequent generations.

\section{Introduction}

The ability of the hallucinogen, lysergic acid diethylamide (LSD-25), to induce chromosomal damage in human leukocytes has been demonstrated in vitro [10, 21]. Additionally, an increase in chromosomal breakage in peripheral leukocytes of users of LSD has also been observed by several investigators $[11,15,20,36]$. During these studies, preliminary evidence of transplacental passage suggested that chromosomal damage to the developing human fetus might be observed following maternal ingestion of LSD during pregnancy $[11,15,36]$. Therefore, additional children exposed to LSD during various times of gestation were investigated.

\section{Materials and Methods}

The mother-child pairs, both of the subject and of the control groups, were volunteers from a middle class 
background and all had completed varying levels of college education. Those with exposure to LSD contacted us primarily as a result of articles in the lay press concerning the possibility of drug-induced chromosomal damage. The control pairs were obtained from laboratory personnel and hospital staff members. All subject pairs underwent an extensive interview by both a psychiatrist (in some instances, two) and a social worker at the Bellevue Hospital Psychiatric Division. Data relative to drug history (particularly LSD), with emphasis on use prior to and during pregnancy, as well as radiation exposure, viral infections, and recent illnesses were obtained independently by both interviewers. Upon comparison of the results, no major discrepancies were observed. Similar information was obtained from the control pairs by the social worker. The two groups had very similar medical histories. Almost all the mothers in both groups had had an x-ray examination of the chest, but no additional radiation exposure. One subject child (12a), exposed to LSD in utero, had had a series of four or five roentgenograms of the skull five months prior to obtaining the blood specimen for cytogenetic evaluation.

The sample consisted of nine children exposed to LSD during pregnancy, four children whose parents used LSD before conception but with no maternal use during pregnancy, the mothers of these children, and six additional adults taking the drug. Four of those children exposed in utero had been previously investigated [11]. The comparison group, matched for age and sex, consisted of 15 normal, healthy individuals (six children and nine adults) who had not ingested the drug (tables I and II).

Chromosomes were obtained from peripheral leukocyte cultures initiated from whole blood inoculum (two drops) grown in commercially available microculture kits [37]. Two replicate blood samples per subject were collected and coded. The microculture tubes were placed in an incubator at $37^{\circ}$ for 72 hours, the last two hours in the presence of $0.5 \mathrm{mg}$ of Vinblastine [38] per tube, and slide preparations were made following a modification of the method of MOORHEAD et al. [27]. Four or five cover slips $\left(22 \mathrm{~mm}^{2}\right)$ were prepared from each subject and mounted randomly, two to a microscope slide. The coded slides, prepared in New York City, were sent to Buffalo, New York, for analysis. Twenty-five well-spread metaphases per cover slip were selected under low power $(\times 250)$ by persons not involved in the scoring of chromosomal damage. Detailed analysis of the cells for chromosomal abnormalities (oil immersion, $\times 2500$ ) was done by one person.

Chromosomal damage was classified as either chromatid or isochromatid breaks; other structural abnormalities were also noted. A chromatid break was defined as a visual discontinuity of the chromatin material in which the distal fragment of a single chromatid was displaced from the axis of the proximal portion. An isochromatid break was defined identically, except that both chromatids were broken at the same level and the distal portions were displaced. Both of these types of abnormalities were scored as single breaks. 'Gaps' or visual discontinuities of the chromatid material without displacement of the distal portion were noted but not considered as breaks. Exchange figures (triradials and quadriradials) and dicentric chromosomes were counted as two breaks.

\section{Results}

The frequencies of chromosomal aberrations observed in the individuals studied are shown in tables I and II. From these observations, a statistically significant difference in 'chromosome break rate' is noted between the control subjects and individuals exposed to LSD.

Table I. Chromosomal damage in control group

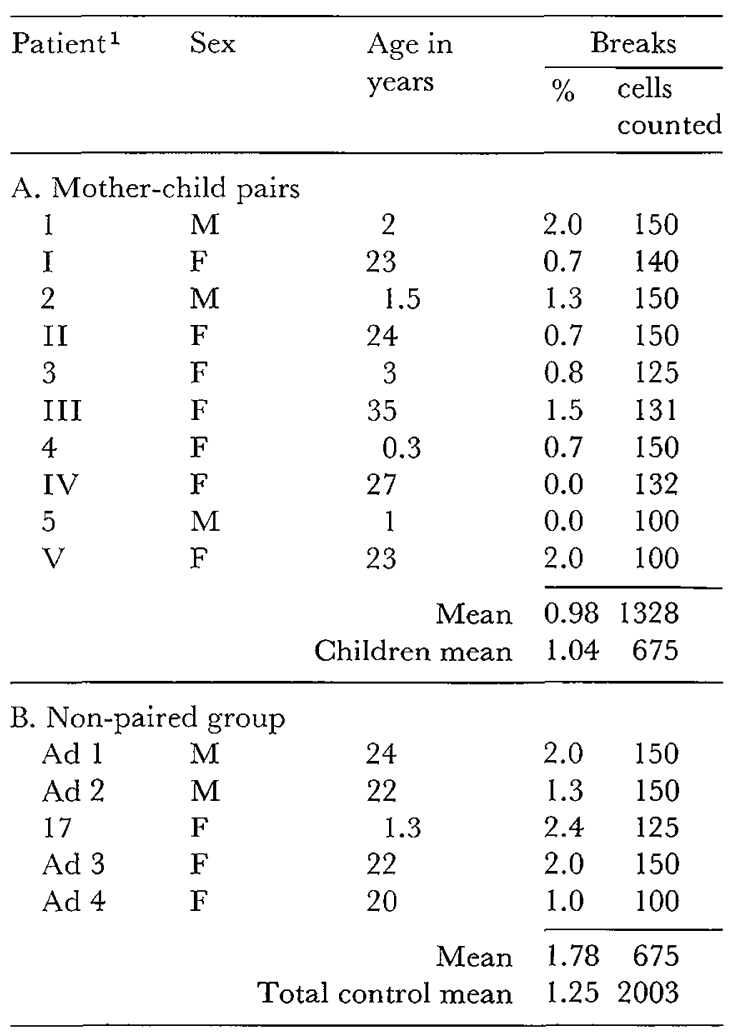

${ }^{1}$ Arabic numerals: children; Roman numerals: mothers; Ad: adults. 
Table II. Chromosomal damage in individuals exposed to LSD.

\begin{tabular}{|c|c|c|c|c|c|c|c|c|c|c|c|}
\hline \multirow[t]{2}{*}{ Patient ${ }^{1}$} & \multirow{2}{*}{$\begin{array}{l}\text { Age in } \\
\text { years }\end{array}$} & \multirow[t]{2}{*}{ Sex } & \multirow{2}{*}{$\begin{array}{l}\text { No. of } \\
\text { doses }\end{array}$} & \multirow{2}{*}{$\begin{array}{l}\text { No. of } \\
\text { doses } \\
\text { prior to } \\
\text { conception }\end{array}$} & \multirow{2}{*}{$\begin{array}{l}\text { No. of } \\
\text { doses } \\
\text { in utero }\end{array}$} & \multirow{2}{*}{$\begin{array}{l}\text { Interval } \\
\text { between last } \\
\text { dose and } \\
\text { investigation }\end{array}$} & \multicolumn{2}{|c|}{ Breaks } & \multirow[t]{2}{*}{ Comments } & \multirow{2}{*}{$\begin{array}{l}\text { Other } \\
\text { drugs } \\
\text { in utero }^{2}\end{array}$} & \multirow{2}{*}{$\begin{array}{l}\text { Other } \\
\text { drugs } \\
\text { by history }{ }^{2}\end{array}$} \\
\hline & & & & & & & $\%$ & $\begin{array}{l}\text { cells } \\
\text { counted }\end{array}$ & & & \\
\hline \multicolumn{12}{|c|}{ A. Mother-child pairs (In utero) } \\
\hline 6 & 0.33 & $\mathrm{M}$ & & & 30 & $8 \mathrm{mos}$ & 5.3 & 75 & & & \\
\hline VI & 26 & $\mathrm{~F}$ & 36 & 6 & & 3 wks & 6.7 & 150 & & & $\mathrm{~A}, \mathrm{M}, \mathrm{O}$ \\
\hline $7 \mathrm{a}$ & 2 & $\mathrm{~F}$ & & 8 & 7 & $30 \mathrm{mos}$ & 1.3 & 150 & . & $\mathrm{P}, \mathrm{M}$ & \\
\hline $7 \mathrm{~b}$ & 5 & $\mathrm{~F}$ & & & 1 & 5 yrs & 2.0 & 150 & & $\mathrm{~A}, \mathrm{P}, \mathrm{M}$ & \\
\hline VII & 26 & $\mathrm{~F}$ & 20 & & & $30 \mathrm{mos}$ & 4.7 & 150 & & & $\mathrm{~A}, \mathrm{O}, \mathrm{M}, \mathrm{P}, \mathrm{H}$ \\
\hline 8 & 0.55 & $\mathrm{M}$ & & 19 & 1 & $15 \mathrm{mos}$ & 0.0 & 100 & & & \\
\hline VIII & 20 & $\mathrm{~F}$ & 20 & & & $15 \mathrm{mos}$ & 1.0 & 100 & & & $\mathrm{M}, \mathrm{O}, \mathrm{B}, \mathrm{A}$ \\
\hline 9 & 1.6 & $\mathrm{~F}$ & & 2 & 1 & $28 \mathrm{mos}$ & 7.3 & 150 & 1 quadriradial & $\mathrm{M}$ & \\
\hline IX & 22 & $\mathrm{~F}$ & 45 & & & $2 \mathrm{mos}$ & 7.8 & 128 & & & $\mathrm{M}$ \\
\hline 10 & 0.9 & $\mathrm{~F}$ & & & 4 & $14 \operatorname{mos}$ & 19.0 & 300 & 1 dicentric & $\mathrm{M}, \mathrm{H}, \mathrm{C}$ & \\
\hline $\mathrm{X}$ & 21 & $\mathrm{~F}$ & 7 & & & $14 \mathrm{mos}$ & 6.4 & 78 & & & $\mathrm{M}, \mathrm{B}, \mathrm{O}, \mathrm{H}, \mathrm{C}, \mathrm{A}$ \\
\hline 11 & 1.5 & $\mathrm{M}$ & & 5 & 1 & $34 \mathrm{mos}$ & 13.0 & 300 & 1 dicentric & & \\
\hline $\mathrm{XI}$ & 25 & $\mathrm{~F}$ & 15 & & & $3 \mathrm{wks}$ & 20.3 & 300 & 1 quadriradial & & $\mathrm{H}, \mathrm{M}, \mathrm{A}$ \\
\hline $12 \mathrm{a}$ & 0.17 & $\mathrm{M}$ & & 44 & 4 & $6 \mathrm{mos}$ & 4.0 & 200 & & $\mathrm{C}, \mathrm{M}$ & \\
\hline $12 \mathrm{~b}$ & 5.5 & $\mathrm{~F}$ & & 42 & 2 & $5.6 \mathrm{yrs}$ & 7.5 & 200 & & $\mathrm{M}$ & \\
\hline \multirow[t]{3}{*}{ XII } & 28 & $\mathrm{~F}$ & 100 & & & $6 \mathrm{mos}$ & 11.0 & 200 & & & $\mathrm{~A}, \mathrm{P}, \mathrm{H}, \mathrm{C}, \mathrm{M}$ \\
\hline & & & & & & Mean & 9.34 & 2731 & & & \\
\hline & & & & & & Children mean & 9.22 & 1475 & & & \\
\hline \multicolumn{12}{|c|}{ B. Mother-child pairs (prior to conception) } \\
\hline 13 & 1 & $\mathrm{~F}$ & & 6 & & & 2.5 & 118 & & & \\
\hline XIII & 24 & $\mathrm{~F}$ & 6 & & & $24 \operatorname{mos}$ & 3.7 & 80 & & & $\mathrm{~A}, \mathrm{M}$ \\
\hline 14 & 0.66 & $\mathrm{~F}$ & & 11 & & & 2.0 & 150 & & & \\
\hline XIV & 25 & $\mathrm{~F}$ & 11 & & & $24 \mathrm{mos}$ & 6.7 & 150 & & & $\mathrm{M}, \mathrm{H}, \mathrm{A}$ \\
\hline 15 & 0.5 & $\mathrm{M}$ & & & & & 8.7 & 150 & 2 dicentrics & & \\
\hline $\mathrm{XV}$ & 25 & $\mathrm{~F}$ & & 12 & & $12 \mathrm{mos}$ & 8.8 & 125 & & & \\
\hline 16 & 4 & $\mathrm{M}$ & & 1 & & & 2.9 & 150 & & & \\
\hline \multirow[t]{2}{*}{$\mathrm{XVI}$} & 26 & $\mathrm{~F}$ & 20 & & & $30 \mathrm{mos}$ & 4.7 & 150 & & & $\mathrm{~A}, \mathrm{O}, \mathrm{M}, \mathrm{P}, \mathrm{H}$ \\
\hline & & & & & & Mean & 5.03 & 1073 & & & \\
\hline
\end{tabular}


The effect of LSD-25 on the chromosomes of children exposed in utero

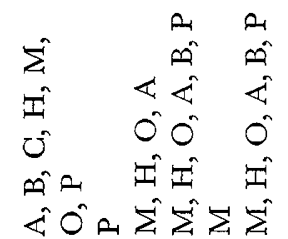

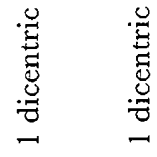

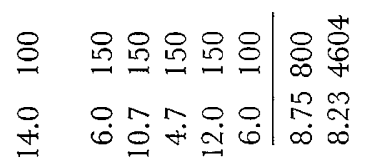

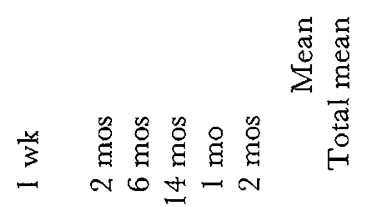

\&

a $\quad \sum \sum \sum \sum$

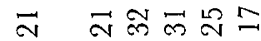

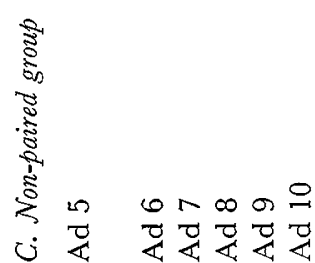

The overall mean of the control group was $1.2 \%$ cells with breaks (range $0.0-2.4 \%$ ) as opposed to $8.2 \%$ breaks (range $0.0-20.3 \%$ ) in the subject group. This difference is statistically significant by the ' $t$ ' test $(p<0.01)$. The control group showed much less variability in chromosomal breakage than did the subject group, and in some cases there was an overlap of values. There was, however, an almost 8-fold increase in chromosomal breakage among individuals exposed to LSD. The response to the drug varied considerably from individual to individual since there was a wide range of values observed in the subject group. Some of these were well within the normal control range.

Disregarding the adults and comparing only those children at 'risk', there was a similar statistically significant difference; $1.0 \%$ breaks in the control subjects, as opposed to $9.2 \%$ breaks in those exposed in utero $(\mathrm{p}<0.01)$. The group of children whose mothers used LSD prior to conception but not during pregnancy (table IIb) exhibited a much lower frequency of chromosomal damage (mean $4 \%$ ). The reliability of at least one mother in this group is questionable, however. She reported no ingestion of the drug during her pregnancy but is otherwise an habitual 'user' of LSD. Her child (15) exhibited a breakage rate of $8.7 \%$ with two dicentric chromosomes. If this child is eliminated from the group, the mean breakage rate of these children decreases from $4 \%$ to $2.4 \%$ as compared with $1 \%$ in the control subjects.

A total of eight chromosomal rearrangements was observed in this study, six dicentric chromosomes and two quadriradial formations. Two dicentrics and one quadriradial were noted in the children exposed in utero, two dicentrics in the child 'exposed' prior to conception, and the remaining quadriradial and two dicentrics were in adults who had ingested the drug. It is important to note that all of the structural rearrangements were observed in the LSD group, while none was seen in the control group. At this time, all of the children in the study, including those exposed to LSD in utero and those born to mothers using LSD prior to conception, are apparently healthy and show no obvious birth defects.

\section{Discussion}

The results of the present investigation reveal a significantly elevated frequency of chromosomal damage among children exposed to LSD when they are compared to matched controls. Those individuals whose mothers ingested LSD prior to but not during pregnancy do not show as striking an increase in chromosomal breaks.

Although in vitro chromosomal damage by LSD has 
been clearly demonstrated $[10,21]$, the question of similar damage subsequent to in vivo LSD ingestion is controversial. Several groups of investigators have observed increased chromosomal breakage in cells from LSD users $[11,15,20,36]$, while others have.been unable to confirm these findings [5, 24, 33]. Several possible explanations for these discrepancies exist because of obvious variables in the populations studied. Most in vivo studies involve the use of illicit LSD, and questions of purity and the exact dosages employed cannot be resolved. This difficulty may be partially overcome by cytogenetic examination of patients receiving LSD for therapeutic reasons. Our initial report [10] described one such case in whom there was noted increased breakage as well as an increase in structural rearrangements (quadriradials). A series of five patients treated with pure LSD showed an elevated frequency of breaks and gaps [29]. Another series of patients, receiving pure LSD for psychotherapy in known dosages [34], has demonstrated a statistically significant increase in structural rearrangements, as well as a transient increase in chromosomal damage. Similarly, Sparkes et al. [33] reported that all but one of the quadriradials and chromosomal interchanges they had noted were observed in LSD 'users' or in those receiving LSD for medical treatment.

The second problem is the concomitant use of additional drugs, a difficulty which is obvious in all of the studies to date and necessitates the assessment of these agents individually. We have tested several of these drugs, notably some of the tranquilizers (chlorpromazine, diazepam and chlordiazepoxide hydrochloride) both in vivo and in vitro and find no suggestion of a chromosome-breaking potential [12].

Environmental influences may also play a role. In assessing those investigations utilizing 'hippie populations', one must consider the overall physical status of the subjects. It is well known that these communal enclaves are rampant with venereal disease, hepatitis, and malnutrition. These may be contributing factors to the results obtained. The subjects of the present report, however, are not from this group, but are more reflective of a 'general population'. Insofar as LSD ingestion was the common selective factor for the individuals studied, it seems plausible that this agent may indeed be the inciter of chromosomal damage. The ultimate evaluation of the cytogenetic effects of LSD in man, however, will require observations made under rigidly controlled circumstances.

The vast majority of damaged chromosomes exhibited chromatid breaks which are of the type generally found after the completion of DNA synthesis $\left(\mathrm{G}_{2}\right)$. Inasmuch as the type of cells used in this study were in the pre-DNA synthetic state $\left(G_{1}\right)$ at the initiation of culture, this observation appears self-contra- dictory; however, three possible mechanisms may account for these findings.

(1) It has been demonstrated recently that aberrations similar to those found in the present study can be observed in normal cells exposed to plasma from irradiated individuals [19], implicating a humoral factor. This finding is unlikely to apply to this study because of the minute amounts of plasma in the specimens collected.

(2) Lymphocytes observed at metaphase after 72 hours of culture are not infrequent in the second or third in vitro division [18, 30], and isochromatid breaks may appear as chromatid breaks due to partial restitution [22]. Since other studies have shown similar differences in chromatid abnormalities between control cultures and those exposed to various agents known to produce chromosome breaks [9], this finding remains a possible explanation.

(3) It is possible that drug-induced metabolic errors or lysosomal membrane instability during $G_{1}$ may lead to the subsequent appearance of chromosomal damage during or after DNA systhesis [2, 3, 25]. To us, this appears to be the most likely explanation.

The potential dangers of agents capable of causing chromosomal breakage must be evaluated from various points of view: (1) the effect on the individual exposed; (2) the teratogenic potential of the agent; and (3) the possibility of a truly genetic effect (transmission through gametes).

That individuals possessing certain chromosomal abnormalities have an increased risk of developing neoplasia, principally leukemia, has been documented [26]. This association between cytogenetic imbalance and neoplasia, although not necessarily causal, apparently obtains whether it is due to an inherited tendency $[7,17,31]$ or induced by exogenous agents $[6,14]$.

Although birth defects in man attributed to LSD have been reported [36], this observation must be interpreted with extreme caution. Considering the relatively high frequency of spontaneous birth defects in the normal population, occurrence of malformed children may indeed be entirely coincidental with ingestion of LSD by the mother. Only a well-controlled study will answer this question. In animals (rats, hamsters and mice) there is documentation of teratogenesis as a direct consequence of LSD injection during pregnancy $[1,4,16]$. WARKANY and TAKACS [35] could not confirm the positive findings in rats. The chromosomes of these malformed fetuses were not examined, but the study of spontaneous abortions in man [8] and mouse [28] indicate that a high proportion of such abortuses carry chromosomal aberrations. Therefore, the possibility exists of chromosomal damage in utero leading to increased numbers of abnormal 
offspring. The fact that many normal children have been born to women ingesting LSD in pregnancy does not necessarily contradict this possibility. From animal studies, it appears that the drug has a limited but highly specific time period during which malformations are produced. It may be that many women who have borne normal children may not have ingested the drug at the critical time. If, indeed, such a critical period exists in man and is early enough in gestation to produce severe malformations and grossly abnormal fetuses, the result in the majority of cases may be abortion, a number of which may be unnoticed.

In our subject sample, exposure of the fetuses to LSD occurred at various times during pregnancy, about half including at least one trimester dose. There was no apparent correlation between time of exposure or number of doses and the frequency of chromosomal damage. All but two of these children were exposed to additional drugs during pregnancy; however, there was no consistent exposure to any single agent except LSD. The two children with the greatest chromosomal damage were also subjected to other hallucinogens. In view of the demonstrated chromosome-damaging potential of at least one additional hallucinogen, psilocybin [32], this result is not surprising. Marijuana, the second common agent involved, showed no consistent correlation with chromosomal breakage. In fact, two of the three children with the lowest damage were exposed to this drug.

Ample evidence from clinical human cytogenetics already exists attesting to the segregation and transmission of chromosomal rearrangements leading to fetal wastage and a high risk of offspring with congenital malformations and mental retardation. To implicate LSD in producing a truly genetic effect necessitates the demonstration of heritable damage to the chromosomes of the gametes. Such studies are difficult to perform in man since they involve direct observation on germinal cells from gonadal biopsies. Evidence from the meiotic chromosomes of mice injected with LSD, however, indicates that the drug is capable of inflicting damage on the chromosomes of meiotic as well as somatic cells $[13,32]$. If gametes containing such abnormal chromosomes are viable and functional, then the ingestion of LSD may have a true genetic effect on subsequent generations.

\section{Conclusion}

The ingestion of LSD-25 by mothers during pregnancy resulted in apparent increased prevalence of chromosomal abnormality in her offspring. Although still present in abnormally increased amounts, such aberrations were less common in children whose mothers had taken the drug prior to but not during pregnancy. The changes in chromosomal morphology could be related neither to dose nor duration of administration, and the effects were detected in both children and mothers many months after exposure. The possible consequences and significance of these changes either to the children or to their offspring remains uncertain. Nevertheless, agents capable of inflicting chromosomal damage must be treated with extreme caution until the genetic implications of these observations can be unambiguously established.

\section{References and Notes}

1. Alexander, G.J.; Miles, B.E.; Gold, G.M. and Alexander, R. B.: LSD: Injection early in pregnancy produces abnormalities in offspring of rats. Science 157: 459 (1967).

2. Aluxson, A. G. and Mallucar, L.: Histochemical studies of lysosomes and lysosomal enzymes in virus injected cell cultures. J. exp. Med. 121: 463 (1965).

3. Allison, A.C. and Paton, G.R.: Chromosome damage in diploid cells following activation of lysosomal enzymes. Nature, Lond. 207: 1170 (1965).

4. Auerbach, R. and Rugowski, J. A.: Lysergic acid diethylamide : Effect on embryos. Science 155: 1325 (1967).

5. Bender, L. and Sankar, D.V.S.: Chromosome damage not found in leukocytes of children treated with LSD-25. Science 159: 749 (1968).

6. Brzzozero, O.J.; Johnson, K. G. and Grocco, A. : Radiation-related leukemia in Hiroshima and Nagasaki, 1946-64. I. Distribution, incidence and appearance time. New Engl. J. Med. 274: 1095 (1966).

7. Bloom, G. E.; Warner, S.; Gerald, P.S. and DiaMOND, L. K.: Chromosome abnormalities in constitutional aplastic anemia. New Engl.J. Med. 274: 8 (1966).

8. CARR, D.H.: Chromosome anomalies as a cause of spontaneous abortion. Amer.J. Obstet. Gynec. 97: 283 (1967).

9. Cohen, M.M. and Shaw, M.W.: Specific effects of viruses and antimetabolities on mammalian chromosomes; in In vitro, the chromosome: Structural and functional aspects (ed. DAwE, C.J.) (Williams and Wilkins, Baltimore, Md. 1965).

10. Cohen, M.M.; Marinello, M.J. and Back, N.: Chromosomal damage in human leukocytes induced by lysergic acid diethylamide. Science 155 : 1417 (1967).

11. Cohen, M.M.; Hirschiorn, K. and Frosch, W.A.: In vivo and in vitro chromosomal damage induced by LSD-25. New Engl.J. Med. 277: 1043 (1967). 
12. Cohen, M.M.; Hirschiorn, K. and Frosch, W.A.: Cytogenetic effects of several tranquilizing drugs in vivo and in vitro: A negative study (in preparation).

13. Cohen, M.M. and Mukherjee, A.B.: Meiotic chromosome damage induced by LSD-25. Nature, Lond. 219: 489 (1968).

14. Court Brown, W.M. and Doll, R.: Mortality from cancer and other causes after radiotherapy for ankylosing spondylitis. Brit.med.J. 2: 1327 (1965).

15. Egozcue, J.; Irwin, S. and Maruffo, C. A. : Chromosomal damage in LSD users. J. amer. med. Ass. 204: 214 (1968).

16. Geber, W.F.: Congenital malformations induced by mescaline, lysergic acid diethylamide and bromolysergic acid diethylamide in the hamster. Science 158: 265 (1967).

17. Heght, F.; Kileer, R.D.; Rigas, D.A.; Dahnke, G.S.; Gase, M.P.; Trsdale, V. and Miller, R.W.: Leukemia and lymphocytes in ataxiatelangiectasia. Lancet $i i: 1193$ (1966).

18. Heddle, J.A.; Evans, H.J. and Scotr, D.: Sampling time and the complexity of the human leukocyte culture system; in Human radiation cytogenetics (ed. Evans, H.J.; Court Brown, W.M. and McLean, A.S.), p. 6 (Wiley, New York, N.Y. 1967).

19. Hollowell, J. G. and Litrlefield, L.G.: Chromosome damage induced by plasma from irradiaated patients. J.S. C. med. Ass. 63 (1967).

20. Irwin, S. and Egozcue, J.: Chromosomal abnormalities in leukocytes from LSD-25 users. Science 157: 313 (1967).

21. JARViK, L.F. and KATO, T.: Is lysergic a teratogen? Lancet $i$ : 250 (1968).

22. LeA, D.E.: Actions of radiation on living cells, 2nd ed. (Cambridge University Press, Cambridge, Mass. 1955).

23. Lrsco, H. and Lrsco, E.: Personal communication (1968).

24. Loughman, W.D.; Sargent, T.W. and IsraetSTAM, D.M.: Leukocytes of humans exposed to lysergic acid diethylamide: Lack of chromosomal damage. Science 158: 508 (1967).

25. Malluci, L. and Alurson, A. G.: Lysosomal enzymes in cells infected with cytopathic and noncytopathic viruses. J. exp. Med. 121: 477 (1965).
26. Miller, R.W.: Persons with exceptionally high risk of leukemia. Cancer Res. 27: 2420 (1967).

27. Moorhead, P.S.; Nowell, P.G.; Mellman, W.J.; Battips, D. M. and Hungerford, D. A.: Chromosome preparations of leukocytes cultured from human peripheral blood. Exp. Cell Res. 20: 613 (1960).

28. Mukherjee, A. B.: Unpublished data.

29. Nielsen, J.; Friedrich, U. and Tsuboi, T.: Chromosome abnormalities and psychotropic drugs. Nature, Lond. 218: 488 (1968).

30. Sasaki, M.S. and Norman, A.: Proliferation of human lymphocytes in culture. Nature, Lond. 210: 913 (1966).

31. Sawitsky, A.; Bloom, D. and German, J.: Chromosomal breakage and acute leukemia in congenital telangiectatic erythema and stunted growth. Ann. intern. Med. 65: 487 (1966).

32. Skakkebaek, N.E.; Phillip, J. and Rafaelson, O.J.: LSD in mice: Abnormalities in meiotic chromosomes. Science 160: 1246 (1968).

33. Sparkes, R.S.; Melnyk, J. and Bozzetti, L.P.: Chromosomal effect in vivo of exposure to lysergic acid diethylamide. Science 160: 1343 (1968).

34. TAylor, K.M.; Hungerford, D.A.; LaBadie, G.U.; Balaban, G.B. and Paton: Gytogenetic effects of LSD therapy in man. J.amer. med.Ass. (in press).

35. WARKANY, J. and TAKacs, E.: Lysergic acid diethylamide (LSD): No teratogenicity in rats. Science 159: 731 (1968).

36. Zellweger, H.; MaDonald, J.S. and Abbo, G.: Is lysergic acid diethylamide a teratogen? Lancet ii: 1066 (1967).

37. Chromosome Medium IA, Grand Island Biological Co., Grand Island, New York.

38. In the form of Velban, Eli Lilly Co., Indianapolis, Indiana.

39. This work was supported in part by grants from the US Ghildren's Bureau (Project No.417) and the US Public Health Service (HD-02552 and MH08618).

40. Dr. HirschHorn is a career scientist of the New York City Health Research Council (I-513).

41. Requests for reprints should be addressed to: Marmon M. Cohen, Ph.D., Division of Human Genetics, 86 Hodge Avenue, Buffalo, N.Y. 14222 (USA). 